Methods: Subjects were AS patients enrolled in the Korean College of Rheumatology Biologics registry KOBIO, Dec $2012 \sim$ ). All approved and commonly prescribed TNFi were included in the analysis. Discontinuation was defined as switching or stopping the biologic agent. Kaplan-Meier curve and Cox proportional hazard model were used for further analysis. Reason of TNFi discontinuation was also assessed. Univariate and multivariate analyses were used to identify possible predictors of discontinuation.

Results: Data of total of 1005 AS patients were analysed (median follow-up period: 14 months). The mean age of patients was 40.7 , and $77.4 \%$ were males. The mean disease duration was 7.1 years, HLA-B27 were positive in $82.4 \%$, and $33.2 \%$ of patients had lesion(s) of syndesmophytes. Seventy-six percent of patients were first-time biologic users. Discontinuation of TNFi occurred in $24.2 \%$ (switching in $9.6 \%$ ) of patients during follow-up. The drug survival function estimate showed that the adjusted hazard ratio (HR) of golimumab (compared with etancercept) was $0.441(95 \% \mathrm{Cl} 0.277-0.703, \mathrm{p}<0.001)$. The reason of discontinuation was inefficacy $(32.6 \%)$, adverse events (23.6\%), clinical improvement $(11.2 \%)$, and others (32.6\%). A multivariate analysis indicated predictors of discontinuation to be shorter disease duration ( $H R$ 0.973, $\mathrm{p}=0.044$ ), and negative HLA-B27 (HR 1.623, $p=0.0093$ ).

Conclusions: Our study demonstrates that few AS patients switched to other TNFi during their course of treatment. The drug retention rate of golimumab was higher compared with other agents prescribed in Korean AS patients.

Disclosure of Interest: None declared

DOI: 10.1136/annrheumdis-2018-eular.4988

\section{SAT0280 RAPAMYCIN RESTORES THE BALANCE BETWEEN TH17 AND REGULATORY T CELLS IN USPA PATIENTS}

F. Jinnan ${ }^{1}$, X. Dan ${ }^{1}$, G. Chong ${ }^{2}$, L. Xiaofeng ${ }^{1} .{ }^{1}$ The Second hospital of Shanxi Medical University, Taiyuan, China; ${ }^{2}$ Brigham and Women's Hospital, Boston, USA

Background: The association of undifferentiated spondyloarthritis (uSpA) with the imbalance of Th17/Treg cells is still unclear. By inhibiting mTOR, rapamycin promotes the proliferation of Treg cells and inhibits the growth of Th17 cells.

Objectives: Therefore, we aimed to investigate the status of Treg and Th17 cells in uSpA patients and explore the therapeutic effect of Rapamycin on uSpA patients with imbalanced of Th17 and Treg cells.

Methods: Two hundred thirty-seven new onset uSpA patients and 93 healthy controls were enrolled. These patients fulfilled ESSG criteria for SpA but did not fulfill the criteria for any established disease of the group. Both absolute numbers and proportions of Treg (CD4 +CD25+Foxp3+T) and Th17 (CD4 + IL-17+T) cells in peripheral blood were analysed by flow cytometry. The 21 new onset Patients with imbalance of Th17/Treg cells were treated with rapamycin at a dose of $0.5 \mathrm{mg}$ twice for a weeks or every 2 days for 6 weeks combined with conventional treatment (salazosulfapyridine $500 \mathrm{mg}$ three times per day; etoricoxib $60 \mathrm{mg}$ once per day or other NSAIDs drugs).

Results: Increase in absolute number and percentage of Th17 (Th17\% 1.11 \pm 0.66 vs $2.43 \pm 1.21, p<0.05$; Th17 cells/ $\mu$ l 7.54 \pm 4.07 vs $19.54 \pm 18.45, p<0.05$ ) and decrease in those of Tregs (Treg\% $4.8 \pm 1.60$ vs $3.35 \pm 1.76, p<0.05$; Treg cells $/ \mu$ l (33.77 \pm 13.67 vs $27.79 \pm 28.62, p<0.05)$ were found in $18.6 \%(44 / 237)$ of patients with $\mathrm{uSpA}$ as compared with that of healthy controls. The patients with imbalance of Th17/Treg cells displayed higher BASDAI scores and ESR as compared with other uSpA patients [BASDAI $(3.27 \pm 1.06$ vs $1.13 \pm 0.91 \mathrm{P}<0.05)$; ESR (29.27 \pm 19.32 vs $21.80 \pm 18.34 \mathrm{P}<0.05)]$. The absolute count of Th17 in 21 patients received rapamycin reduced after 6 weeks $(12.35 \pm 11.00$ vs $6.69 \pm 5.54, p<0.05)$ whereas that of Treg cells showed increase trend but the difference did not reach statistical significance.

Conclusions: Absolute number of Treg decreased and that of Th17 cells increased in the peripheral blood of uSpA patients, suggesting that imbalance of the two subsets contributes to the pathogenesis of uSpA. Rapamycin recovered the balance between Th17 and Treg cells in uSpA patients by reducing Th17 cells.

\section{REFERENCES:}

[1] Cruzat V, et al. Undifferentiated spondyloarthritis: recent clinical and therapeutic advances. J. Curr Rheumatol Rep 2010 Oct;12(5):311-317.

[2] da Cruz Lage R, et al. Undifferentiated spondyloarthritis in a heterogeneous Brazilian population: an eight-year follow-up study. J. Rheumatol Int 2014 Jul;34(7):1019-1023.

[3] Heather K, et al. Rapamycin inhibits differentiation of Th17 cells and promotes generation of FoxP3+ $\mathrm{T}$ regulatory cells. J. Int Immunopharmacol 2007 Dec;15;7(13):1819-1824

[4] Raychaudhuri SP, et al. IL-23/IL-17 axis in spondyloarthritis-bench to bedside. J. Clin Rheumatol 2016 Jun;35(6):1437-1441.

Disclosure of Interest: None declared

DOI: 10.1136/annrheumdis-2018-eular.4133

\section{SAT0281 BIOLOGICS IN SAPHO SYNDROME. A SYSTEMATIC REVIEW}

D. Daoussis, G. Konstantopoulou, I. Antonopoulos, S.-N. Liossis. Rheumatology, University of Patras Medical School, Rio, Patras, Greece

Background: The SAPHO (Synovitis, Acne, Pustulosis, Hyperostosis, Osteitis) syndrome is a relatively rare clinical entity characterised by a wide range of dermatological and musculoskeletal manifestations. Treatment is largely empiric since guidelines do not exist. Biologics have been used in cases refractory to conventional treatment.

Objectives: To systematically review all cases of patients with SAPHO syndrome treated with biologics to date.

Methods: We performed a systematic electronic search (PubMed) using the key words SAPHO combined with any of the following: treatment, biologics, anti-TNF infliximab, adalimumab, etanercept, certolizumab, golimumab, IL-1, anakinra, canakinumab, IL-17, secukinumab, IL-23, ustekinumab, IL-6, tocilizumab, abatacept, rituximab. The only limit set was English language. The computerised search was supplemented by a manual one on the reference lists of the retrieved articles.

The search identified 461 articles; the abstracts of these articles were assessed in order to identify studies related to the therapeutic use of biologics in patients with SAPHO syndrome. Only 36 articles fulfilled the search criteria and were included in the analysis.

Results: We identified 64 cases treated with biologics (44 with TNF blockers, 7 with IL- 1 blockers, 12 with biologics targeting the IL-23/IL-17 axis and 1 with tocilizumab). Data support a positive effect of anti-TNF treatment in SAPHO with a response rate in bone and joint manifestations of $95.4 \%$. Skin disease also improved in $21 / 29$ cases (response rate $72.4 \%$ ). Data related to IL-1 inhibition in SAPHO are encouraging with most patients (6/7) exhibiting a significant response in musculoskeletal manifestations (response rate 85.7\%). However, IL-1 inhibition is not effective in skin manifestations. Ustekinumab seems to have some efficacy with $2 / 4$ patients responding in skin and $3 / 5$ in bone/joint manifestations. Data related to IL-17 blockade indicate efficacy in skin disease with $4 / 7$ patients responding (response rate $57.1 \%$ ). Joint/bone manifestations improved in $2 / 7$ patients (response rate $28.6 \%$ ).

Conclusions: In SAPHO patients not responding to conventional treatment, TNF blockers should be the first choice. In patients failing TNF blockers, IL-1 inhibitors and biologics targeting the IL-17/IL-23 axis could be used.

Disclosure of Interest: None declared

DOI: 10.1136/annrheumdis-2018-eular.4186

\section{SAT0282 OCCURRENCE OF ANTERIOR UVEITIS IN PATIENTS WITH SPONDYLOARTHRITIS AND PSORIATIC ARTHRITIS TREATED WITH TUMOUR NECROSIS FACTOR INHIBITORS: A RESTROSPECTIVE MONOCENTRIC STUDY COMPARING THE SOLUBLE RECEPTOR TO THE MONOCLONAL ANTIBODIES}

G. Khoury ${ }^{1}$, B. Combe ${ }^{1}$, J. Morel ${ }^{1}$, C. Lukas ${ }^{2} .{ }^{1}$ Rheumatology, Hopital Lapeyronie; ${ }^{2}$ Rheumatology, Hop Lapeyronie, Montpellier Cedex 5, France

Background: The efficacy of tumour necrosis factor inhibitors against anterior uveitis has been shown, but discrepancies remain as to the difference in efficacy between soluble receptor and monoclonal antibodies.

Objectives: The objective of this study was to compare the occurrence of anterior uveitis with soluble receptor and monoclonal antibodies in patients with spondyloarthritis (SPA) and psoriatic arthritis (PA).

Methods: This was an observational, retrospective, monocentric study. Patients attending the rheumatology department of the Montpellier University Hospital for a SPA or a PA and who were prescribed anti-TNF agents between 2000 and 2014 were included in our cohort. Data on the diagnosis of rheumatism, the history of the disease and the extra-articular symptoms were collected from medical records. The risk of uveitis has been interpreted qualitatively (number of subjects with at least one flare of uveitis) and quantitatively (number of uveitis flares for each patient). Logistic regression models were used for qualitative analyses and Poisson models for quantitative analyses.

Results: 429 patients were included ( 302 with SPA and 127 with PA, 203 were treated with a monoclonal antibody as first TNF alpha inhibitor and 226 with the soluble receptor). No difference between monoclonal antibodies and soluble receptor was found in the risk of uveitis occurring during the first year of treatment $(\mathrm{OR}=0.94$ [0.35; 2.54], $\mathrm{p}=0.90$ in qualitative analysis and $\mathrm{R}=0.62[0.26 ; 1.46]$; $\mathrm{p}=0.27$ in quantitative analysis). The risk of uveitis was higher with the soluble receptor for the first-line TNF inhibitors, as well as for all therapeutic lines, but this difference was not statistically significant ( $p=0.09$ and 0.08 respectively in quantitative analysis and 0.68 and 0.53 in quantitative analysis).

Conclusions: In view of our observations, the risk of uveitis does not appear to be significantly higher with the soluble receptor than with the monoclonal 
antibodies in SPA and PA, to recommend systematically the eviction of etanercept in subjects with a moderate risk of developing anterior uveitis.

Disclosure of Interest: None declared

DOI: 10.1136/annrheumdis-2018-eular.3342

\section{SAT0283 $\quad$ SECUKINUMAB 150 MG PROVIDES SUSTAINED IMPROVEMENTS IN THE SIGNS AND SYMPTOMS OF ACTIVE ANKYLOSING SPONDYLITIS WITH HIGH RETENTION RATE: 4-YEAR RESULTS FROM THE PHASE III TRIAL, MEASURE 2}

H. Marzo-Ortega ${ }^{1}$, J. Sieper ${ }^{2}$, A. Kivitz ${ }^{3}$, R. Blanco ${ }^{4}$, M. Cohen ${ }^{5}$, E.M. Delicha ${ }^{6}$, S. Rohrer ${ }^{6}, \mathrm{H}$. Richards ${ }^{6}$ on behalf of MEASURE 2 Study Group. ${ }^{1} N I H R$ LMBRU, LTHT and LIRMM, UoL, Leeds, UK; ${ }^{2}$ University Clinic Benjamin Franklin, Berlin, Germany; ${ }^{3}$ Altoona Center for Clinical Research, Duncansville, USA; ${ }^{4}$ Hospital Universitario Marqués de Valdecilla, Santander, Spain; ${ }^{5}$ McGill University, Montreal, Canada; ${ }^{6}$ Novartis Pharma AG, Basel, Switzerland

Background: Secukinumab, a fully human monoclonal antibody that neutralises IL-17A, has shown significant and sustained improvement in the signs and symptoms of active ankylosing spondylitis (AS) through 3 years in the MEASURE 2 study (NCT01649375). ${ }^{1}$

Objectives: To report the longer-term (4 year) efficacy and safety of subcutaneous (s.c.) secukinumab $150 \mathrm{mg}$ in the MEASURE 2 study.

Methods: AS patients ( $p t s ; n=219$ ) were randomised to receive s.c. secukinumab $150 \mathrm{mg}, 75 \mathrm{mg}$ or placebo at baseline, Weeks (Wks) 1, 2 and 3 and every 4 weeks from Wk 4. At Wk 16, placebo-treated pts were re-randomised to receive secukinumab 150/75 mg. Efficacy results are reported for pts initially randomised to secukinumab $150 \mathrm{mg}$ and those who switched from placebo to secukinumab $150 \mathrm{mg}$ at Wk 16 . Safety analyses included all pts who received $\geq 1$ dose of secukinumab. Results are reported as observed.

Results: The retention rate from Wk 16 to 208 was 85\% (85/100) for secukinumab $150 \mathrm{mg}$. Sustained improvements were observed with secukinumab $150 \mathrm{mg}$ across all endpoints through 4 years (Table). These improvements were maintained regardless of prior exposure to anti-TNF therapy; greater responses were demonstrated in anti-TNF-naïve pts. Over the entire study period, the mean exposure $( \pm S D)$ to secukinumab was $1189.3 \pm 452.9$ days. Exposure-adjusted incidence rates (per 100 pt-years) with any secukinumab dose for selected adverse events were: serious infections/infestations (1.5), Candida infections (1.2), Crohn's disease (0.6), major adverse cardiovascular events $(0.6)$, uveitis $(0.6)$, and malignant/unspecified tumours (0.4).

Abstract SAT0283 - Table 1. Clinical improvements with secukinumab $150 \mathrm{mg}$ at Weeks 52 and 208

\begin{tabular}{lcccc}
\hline Variable & Week & \multicolumn{3}{c}{ Secukinumab 150 mg $^{\text {a }}$} \\
\cline { 3 - 5 } & & Total & $\begin{array}{c}\text { Anti-TNF- } \\
\text { naïve }\end{array}$ & $\begin{array}{c}\text { Anti-TNF- } \\
\text { IR }\end{array}$ \\
\hline ASAS20,\% responders (n) & 52 & $74.2(93)$ & $80.0(60)$ & $63.6(33)$ \\
& 208 & $73.3(86)$ & $74.6(59)$ & $70.4(27)$ \\
ASAS40,\% responders (n) & 52 & $57.0(93)$ & $63.3(60)$ & $45.5(33)$ \\
& 208 & $60.5(86)$ & $62.7(59)$ & $55.6(27)$ \\
BASDAI, mean change $\pm S D(n)$ & 52 & $-3.2 \pm 2.3$ & $-3.3 \pm 2.3(60)$ & $-3.0 \pm 2.1$ \\
& & $(93)$ & & $(33)$ \\
& 208 & $-3.2 \pm 2.3$ & $-3.5 \pm 2.4(59)$ & $-2.7 \pm 2.0$ \\
SF-36 PCS, mean change $\pm S D(n)$ & 52 & $7.6 \pm 7.7(94)$ & $8.0 \pm 7.5(61)$ & $6.9 \pm 8.1(33)$ \\
& 208 & $8.3 \pm 8.3(85)$ & $9.4 \pm 8.5(58)$ & $6.2 \pm 7.8(27)$ \\
ASAS partial remission,\% & 52 & $24.7(93)$ & $28.3(60)$ & $18.2(33)$ \\
responders (n) & 208 & $27.9(86)$ & $32.2(59)$ & $18.5(27)$ \\
\hline
\end{tabular}

ancludes placebo switchers. Data are reported as observed.

ASAS; Assessment in SpondyloArthritis International Society; BASDAI, Bath Ankylosing Spondylitis Disease Activity Index; IR, inadequate response; SD, standard deviation; SF-36 PCS, Short Form ${ }^{36}$ Health Survey Physical Component Summary; TNF, tumour necrosis factor

Conclusions: Secukinumab $150 \mathrm{mg}$ provided sustained improvement in the signs, symptoms and physical function in pts with AS through 4 years of treatment with $85 \%$ retention rate. The safety profile of secukinumab remained favourable and was consistent with previous reports. ${ }^{1-3}$

\section{REFERENCES:}

[1] Marzo-Ortega, et al. RMD Open 2017;3:e000592.

[2] Marzo-Ortega, et al. Ann Rheum Dis 2016;75:812-3.

[3] Baraliakos, et al. Clin Exp Rheumatol 2017.
Disclosure of Interest: H. Marzo-Ortega Grant/research support from: Janssen, Celgene, Speakers bureau: Janssen, Pfizer, AbbVie, Celgene, Novartis, UCB, J. Sieper Grant/research support from: AbbVie, Pfizer, Merck, Consultant for: for AbbVie, Pfizer, Merck, UCB, Novartis, Speakers bureau: AbbVie, Pfizer, Merck, UCB, A. Kivitz Grant/research support from: Altoona Centre for Clinical Research, Consultant for: Vertex, AbbVie, Amgen, Celgene, Horizon, Genetech, Janssen, Merck, Novartis, Pfizer, UCB, Genzyme, Sanofi, Regeneron, SUN Pharma Advanced Research, Boehringer Ingeleheim, R. Blanco Grant/research support from: Abbvie, MSD, Roche, Consultant for: AbbVie, Pfizer, Roche, Bristol-Myers, Janssen, Lilly, MSD, Speakers bureau: AbbVie, Pfizer, Roche, Bristol-Myers Janssen, Lilly, MSD, M. Cohen Consultant for: Abbvie, Amgen, BMS, Celgene, Janssen, Lilly, Merck, Novartis, Paladin, Pfizer, Roche, Sanofi, UCB, E. M. Delicha Employee of: Novartis, S. Rohrer Employee of: Novartis, H. Richards Employee of: Novartis

DOI: 10.1136/annrheumdis-2018-eular.3703

\section{SAT0284 AN ADD-ON TRAINING PROGRAM INVOLVING BREATHING EXERCISES, COLD EXPOSURE, AND MEDITATION ATTENUATES INFLAMMATION AND DISEASE ACTIVITY IN AXIAL SPONDYLOARTHRITIS}

G.A. Buijze ${ }^{1}$, H.M.Y. De Jong ${ }^{2}$, M. Kox ${ }^{3}$, D. van Schaardenburg ${ }^{2}$, R.M. van Vugt ${ }^{4}$, C. Popa ${ }^{5}$, P. Picckers ${ }^{3}$, D.L. Baeten ${ }^{2} .{ }^{1}$ Orthopaedic Surgery, ${ }^{2}$ Clinical immunology and rheumatology, Academic Medical Center, Amsterdam; ${ }^{3}$ Intensive Care Medicin, Radboud University Medical Centre, Nijmegen; ${ }^{4}$ Rheumatology, VU medical center, Amsterdam; ${ }^{5}$ Rheumatology, Sint Maartenskliniek, Nijmegen, Netherlands

Background: A training program involving breathing exercises, cold exposure, and meditation (further referred to as: 'add-on training program') was shown to exert immunomodulating properties in healthy individuals undergoing experimental endotoxemia.

Objectives: Assessment of safety and anti-inflammatory effects of the add-on training program in patients with axial spondyloarthritis $(\mathrm{axSpA})$.

Primary objectives: safety (24 weeks) and change in serum CRP levels (week 8 ) Secondary objectives: changes in erythrocyte sedimentation rate (ESR), serum calprotectin levels, disease activity as measured by the ASDAS-CRP and Bath Ankylosing Spondylitis Disease Activity Index (BASDAI), quality of life measures (SF-36, EQ-5D), and hospital anxiety and depression scale (HADS)

Methods: 24 patients with moderatly active axSpA (ASDAS >2.1 and $\mathrm{CRP}>5 \mathrm{mg} / \mathrm{L}$ ) were included in this trial. The intervention consisted of an 8 weeks add-on training program comprising three elements: breathing exercises (cyclic hyperventilation followed by breath retention), gradual cold exposure (immersions in ice cold water), and meditation (third eye meditation). An open-label randomised one-way crossover design was used to rule out regression to the mean by comparing an intervention group with a control group.

\section{CRP}

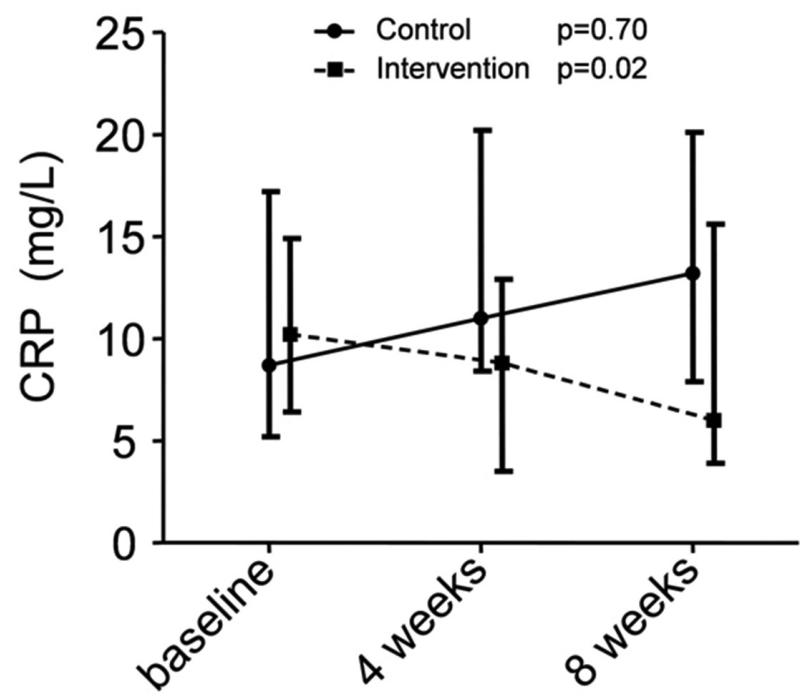

Results: There was no significant difference in adverse events between groups, with one serious adverse event (hypertensive crisis) occurring 8 weeks after end of the intervention and judged 'unrelated'. The study met its primary efficacy endpoint, with a significant decline in serum CRP at week 8 in the intervention group 